\title{
The Alberta Health Services Emergency Strategic Clinical Network Quality Improvement and Innovation forum 2021.
}

\section{Patrick McLane and Eddy Lang on behalf of the Emergency Strategic Clinical Network}

Evidence-based research and quality improvement work are pivotal to health systems meeting their goals. Translating findings and disseminating innovative practices to new settings occurs in part through knowledge translation events, such as conferences and workshops.

The Emergency Strategic Clinical Network ${ }^{\mathrm{TM}}$ (ESCN) Quality Improvement and Innovation forum fills a gap between local and national events. It is devoted to sharing methods and results of emergency department projects in Alberta among those working in emergency care. 2021 was the third consecutive year the ESCN has held this event.

The event provides an opportunity for those working on quality improvement in emergency medicine to network with one another, share innovative projects, share know how and translate promising works to new settings. In addition, the event provides an opportunity to identify projects for potential development through local, provincial, or national funding opportunities.

In light of the ongoing pandemic, this year's forum was held virtually with the support of the University of Calgary Continuing Medical Education group. Funding was kindly provided by the College of Physicians and Surgeons of Alberta. Nineteen teams presented their projects orally. Invited nurse and clinician scientists ranked all submissions to the forum, and the top ranked submissions were recognized in the following categories:

\begin{tabular}{|c|c|c|}
\hline Category & Awardee(s) & Project Title \\
\hline Nurse Led & Christopher Picard & $\begin{array}{l}\text { The clinical effects of CPR meter on chest compression } \\
\text { quality: } a \text { QI project }\end{array}$ \\
\hline Rural Project & $\begin{array}{l}\text { Monika Johnson, Sharon } \\
\text { Reece, Kristin Simard, } \\
\text { Simon Ward }\end{array}$ & $\begin{array}{l}\text { Use of virtually-facilitated simulation to improve } \\
\text { COVID-19 preparedness in rural and remote Canada }\end{array}$ \\
\hline Resident Ked & Jason Elizinga & $\begin{array}{c}\text { Increasing rates of computed tomography use in the } \\
\text { emergency department: identifying targets for quality } \\
\text { improvement }\end{array}$ \\
\hline Medical Student Led & Megg Wiley & $\begin{array}{c}\text { Practice variation in the management of incomplete } \\
\text { and missed spontaneous abortion: a multisite quality } \\
\text { improvement project }\end{array}$ \\
\hline
\end{tabular}

Submissions by ESCN staff and the event sponsor were not eligible for recognition.

A new feature this year was a presentation by ESCN patient advisors on their perspectives on quality improvement, which was well received by all.

Strong attendance shows the value practitioners see in the forum. In 2021, the forum was attended by approximately 140 educators, managers, nurses, physicians and researchers from across Alberta. This is a marked increase over previous years. Post-event evaluation survey feedback suggests that the online format was greatly appreciated and made the event more 
accessible. Requests for more rural oriented content in event feedback may also indicate that the event drew more rural attendees this year.

We are pleased to partner with the Canadian Journal of Emergency Nursing to make abstracts from the event widely available. Individual presenters have had the option of submitting their abstracts for publication in CJEN. In some instances, abstracts have already been published through other conferences and so could not be submitted to CJEN.

The findings presented in the abstracts are solely the work of the submitting authors. The ESCN does not guarantee the accuracy of any reported information. The views expressed in the abstracts are solely the views of the authors and do not represent the ESCN or Alberta Health Services.

Correspondence to: emergencyscn@ahs.ca 